\title{
Strategi 'Marketing Public Relations' Perguruan Tinggi Islam Swasta: Peluang dan Tantangan di Era MEA
}

\author{
${ }^{1}$ Tresna Wiwitan, ${ }^{2}$ Neni Yulianita \\ 1,2Komunikasi, Universitas Islam Bandung, Jl. Tamansari No.1 Bandung 40116 \\ E-mail: ${ }^{1}$ tresnawiwitan@yahoo.com, ${ }^{2}$ yulianita.neni@gmail.com
}

\begin{abstract}
Abstrak: Di era MEA ini Unisba dan Unissula harus kerja keras dalam upaya bersaing dengan perguruan tinggi yang ada di ASEAN. Marketing Public Relations (PR) merupakan sinergi antara kegiatan marketing dengan strategi public relations, dengan Marketing $P R$ diharapkan perguruan tinggi dapat menciptakan dan memperkuat brand sebagai perguruan tinggi Islam yang mempunyai citra dan reputasi yang baik. Penelitian ini bertujuan mengkaji, menganalisis perencanaan Marketing $P R$, dan peluang serta tantangan Marketing $P R$ di era MEA, dengan menggunakan penelitian kualitatif pendekatan studi kasus. Teori yang digunakan adalah Teori Manajemen Relasi (Ledingham) dan Analisis SWOT. Hasil Penelitian, (1) Dalam menyusun perencanaan Marketing $P R$, Humas harus melakukan manajemen relasi dengan siswa, guru/sekolah, orangtua, wartawan dan stakeholders melalui komunikasi yang berkesinambungan; (2) Peluang dan tantangan startegi Marketing PR dalam analisis SWOT dapat dilihat dari aspek: (a) Strategi Strengths-Oppurtunities, yaitu mempertahankan dan memperkuat nilai Islam dalam kegiatan Marketing PR; (b) Strategi Weaknesses-Oppurtunities, yaitu mengedukasi publik internal tentang konsep Public Relations dan Marketing PR; (c) Strategi Strengths-Treats, artinya di era MEA ini PTIS harus meningkatkan kerjasama dengan stakeholders di dalam maupun luar negeri; dan (d) Strategi Weaknesses-Treats adalah meningkatkan kualitas akademik dosen dan mahasiswa, serta mutu pelayanan prima bagi publik internal dan eksternal.
\end{abstract}

Kata kunci: analisis SWOT, marketing PR, strategi

\begin{abstract}
In the era of MEA Unisba And Unissula have to work harder in order to compete with other universities in ASEAN. Marketing Public Relations is a synergy between marketing activities and public relations strategy, by implementation of marketing public relations, it is expected that universities can creates and strengthens their brands as the Islamic universities that have good images and reputations. This research aimed to study and analyze the planning of Marketing Public Relations: the challenges and opportunities of marketing $P R$ in the era of the MEA, by using qualitative research method and case study approach. The theories that used to analyze the research were relation management theory (Ledingham) and SWOT analysis. Results of the research, (1) In preparing the planning of marketing $P R, P R$ should perform management relations with Students, teachers/schools, parents, journalists stakeholders through communications continously; (2) Opportunities and challenges strategies of marketing PR based on SWOT analysis can be seen from some aspects: (a) Strength-opportunity strategy, ie maintain and strengthen the Islamic values in the marketing PR activities; (b) Weaknesses-Oppurtunities strategy, ie to educate the internal public about the concept of Public Relations and Marketing PR; (c) Strength-Treats strategy, meaning that in the era of MEA, PTIS must improve the cooperation with stakeholders in the domestic and foreign country; and (d) Weaknesses-Treats strategy is to increase the academic quality of lecturer and student as well as the quality of service excellent for insider and outsider.
\end{abstract}

Keywords: PR marketing, strategic, SWOT analysis 


\section{PENDAHULUAN}

Masyarakat Ekonomi ASEAN (MEA) digagas untuk membentuk pasar tunggal dan menciptakan kondisi yang kompetitif antarnegara demi peningkatan negara-negara anggota. Isu Masyarakat Ekonomi ASEAN kini menjadi perhatian dan kajian para pelaku pendidikan, terutama perguruan tinggi. Di tengah masalah kesenjangan mutu pendidikan yang tajam di Indonesia, muncul keraguan mengenai kesiapan perguruan tinggi di era MEA. Bangsa Indonesia mempunyai pekerjaan rumah yang cukup besar, tingkat pendidikan, ekonomi masih cukup tertinggal dibandingkan negara Singapore dan Malaysia. Menteri Keuangan, Sri Mulyani Indrawati dalam kuliah umum Mahasiswa Fakultas Hukum Universitas Indonesia (UI) menyatakan: "Saat ini terjadi ketimpangan di antara masyarakat, indikator kesenjangan Indonesia meningkat tajam dari 30 pada 2003 ke 41 pada tahun 2014. Ketimpangan sosial ini terjadi di bidang ekonomi, layanan kesehatan, dan kualitas pendidikan" (Pikiran Rakyat, 27 Juli 2016).

Komitmen MEA ini membuka peluang untuk mobilitas delapan tenaga terampil lulusan perguruan tinggi Indonesia bidang keinsinyuran, arsitek, keperawatan, dokter, kedokteran gigi, tenaga profesional pariwisata, surveyor, dan jasa akuntansi untuk bekerja di kawasan ASEAN tanpa hambatan (http://aeccenter.kemenag.go.id/duniapendidikan-menghadapi-mea-2015). Perguruan Tinggi Islam Swasta (PTIS) sebagai salah satu komponen kehidupan bangsa dan negara, berkewajiban untuk mensyukuri nikmat Allah sesuai dengan fungsinya, berusaha secara terus menerus mengambil bagian dalam membina manusia beriman dan berakhlak luhur dalam meningkatkan kesejahteraan dan kecerdasan bangsa melalui bidang pendidikan. Mantan Ketua Umum Badan Kerjasama Perguruan Tinggi Islam
Swasta (BKS-PTIS), Muhadjir Effendy, menyatakan bahwa; saat ini Perguruan Tinggi Islam Swasta menghadapi tiga tantangan besar, yaitu tantangan kelembagaan yang terdiri dari persaingan dengan Perguruan Tinggi Negeri (PTN) dan hadirnya perguruan tinggi korporasi dan berjaringan internasional. Serta tantangan program internal, yakni, lemahnya Program Studi Keislaman yang harusnya menjadi ciri khas PTIS. Lebih lanjut, Muhadjir merinci, tantangan persaingan dengan PTN tak bisa dihindari karena amanah UU memang memberi peluang PTN menyelenggarakan pendidikan bagi masyarakat luas. Selain itu tantangan yang harus dihadapi oleh perguruan tinggi islam swasta secara internal adalah bagaimana memperkuat determinasi prodi keislaman. Fakta yang terjadi justru sebaliknya, prodi umum lebih berkembang dibandingkan program studi islam.

Universitas Islam Bandung (Unisba) dan Universitas Islam Sultan Agung Semarang (Unissula) merupakan Perguruan Tinggi Islam Swasta yang tergabung dalam BKS-PTIS dan tidak dipengaruhi oleh organisasi massa (ormas) Islam manapun. Inilah yang menjadi branding Unisba dan Unissula, sama-sama mengedepankan Perguruan Tinggi Islam Swasta. Branding dilakukan oleh suatu perusahaan/lembaga untuk melakukan penetrasi pasar dan reinforcement product atau jasa, branding adalah sebuah usaha untuk memperkuat posisi produk dalam benak konsumen (Soemanagara, 2012:98-99). Unisba dan Unissula merupakan Perguruan Tinggi Islam Swasta yang telah menguasai local brand/regional brand, dimana sama-sama mengusai pasar lokal untuk bidang lembaga Pendidikan Tinggi Islam. Dengan dimulainya Masyarakat Ekonomi ASEAN (MEA) diharapkan Perguruan Tinggi Islam Swasta dapat bersaing dengan perguruan tinggi lainnya 
di negara-negara ASEAN.

Marketing Public Relations merupakan salah satu konsep yang dapat digunakan dalam kegitan promosi di perguruan tinggi, dimana marketing $P R$ merupakan sinergi antara strategi pemasaran dengan kegiatan public relations. Oleh karena itu, kami melakukan penelitian mengenai Strategi Marketing PR di Unisba dan Unissula. Perguruan Tinggi Islam Swasta harus mempunyai strategi Marketing PR yang tepat dalam upaya melakukan promosi kepada calon mahasiswa. Penelitian ini diharapkan dapat membantu Humas PTIS membuat strategi Marketing PR di era Masyarakat Ekonomi ASEAN, sehingga mampu bersaing dengan perguruan tinggi swasta lainnya.

Dari rumusan masalah yang telah diuraikan, maka maksud dari penelitian ini adalah untuk menjelaskan, mengungkapkan; "Strategi Marketing Public Relations di Universitas Islam Bandung dan Universitas Islam Sultan Agung Semarang: Peluang dan Tantangan di Era MEA"

Penelitian ini bertujuan untuk mendapatkan pengetahuan dan pemahaman secara mendalam serta dapat menemukan dan mengungkap: (1) Perencanaan dan pengembangan Marketing PR di Unisba dan Unissula; (2) Analisis SWOT dalam strategi Marketing PR di Unisba dan Unissula.

Thomas L. Harris menyatakan bahwa, perencanaan marketing PR termasuk ke dalam perencanaan PR dalam mendukung sasaran dan strategi marketing. Perencanaan Marketing PR merupakan aplikasi dari proses operasional PR dalam upaya menyelesaikan permasalahan pemasaran. Proses operasional PR Cutlip, Center, dan Broom (Harris, 1991): (1) Defining PR Problem. Tahapan ini bertujuan mencari data dan fakta di lapangan dalam upaya penetapan permasalahan PR. Pada tahap ini operasionalisasinya meliputi langkahlangkah dalam upaya mencari dan mengumpulkan data-data yang dilakukan PR dalam bentuk opini publik, sikap publik, dan perilaku publik; (2) Planning and Programming. Tahapan ini sangat menentukan suskesnya pekerjaan PR secara keseluruhan, penyusunan planning harus berpijak pada data dan fakta; (3) Taking Action and Communicating. Merupakan tahapan pelaksanaan dari kegiatan PR sesuai dengan perencanaan dan program yang sudah dirumuskan; (4) Evaluating the Program. Tahap terakhir ini dilakukan untuk mengetahui apakah pelaksanaannya berdasarkan rencana atau tidak dan apakah perlu dirubah atau tidak. Tujuan dari evaluasi ini adalah untuk mengetahui apakah kegiatan PR benarbenar dilaksanakan sesuai perencanaan dari hasil data dan fakta dilapangan.

Teori ini menjadi salah satu teori penting public relations, karena terkait dengan fungsi dasar public relations, yaitu aktivitas komunikasi yang menghubungkan organisasi dengan publik. Teori ini fokus membahas proses manajemen relasi antara organisasi dan publiknya, internal maupun eksternal, karenanya teori ini dikenal sebagai pusat atau inti public relations. (Kriyantono, 2014). John Ledingham (Heath, 2005), mendefinisikan hubungan publik dengan organisasi seperti situasi yang terjadi di antara organisasi dengan publiknya yang didalamnya tindakan kedua belah pihak dapat berdampak pada aspek ekonomi, sosial, budaya, atau politik dari masingmasing pihak.

Upaya yang dilakukan humas Unisba dan Unissula melalui kegiatan marketing public relations, kampanye media massa merupakan kegiatan komunikasi yang dilakukan perguruan tinggi dengan stakeholders dalam upaya membangun relasi.

Analisis SWOT diterapkan untuk melakukan riset tentang lingkungan 
eksternal dan internal, Otto Lerbinger (Gregory, 2002) menyatakan bahwa analisis SWOT digunakan sebagai 'pemantau lingkungan' (environmental monitoring) atau scanning. Dua elemen pertama dari analisis ini adalah Strength dan Weaknesses sebagai faktor yang digerakkan secara internal dan bersifat khusus terhadap lembaga. Dua elemen lain, Opportunities dan Threats yang bersifat eksternal.

Analisis SWOT dalam konteks penelitian ini digunakan dalam upaya membuat strategi Marketing Public Relations di era Masyarakat Ekonomi ASEAN (MEA), bagaimana peluang dan tantangan Perguruan Tinggi Islam Swasta dalam menghadapi persaingan dengan perguruan tinggi lain di era MEA.

\section{METODE}

Penelitian ini menggunakan penelitian kualitatif, dalam upaya menelaah Strategi Marketing PR di Unisba dan Unissula: Peluang dan Tantangan di Era MEA. Berusaha memahami, menginterpretasikan atau menafsirkan perencanaan Marketing PR yang dilakukan Humas Unisba dan Unissula dan mengkaji strategi Marketing $P R$ dari konsep Analisis SWOT.

Studi kasus (case study) yaitu, pendekatan untuk mempelajari, menerangkan, atau menginterpretasikan suatu kasus (case) dalam konteksnya secara natural tanpa adanya intervensi dari pihak luar(Yin, 2011). Peneliti melakukan komparasi terhadap perencanaan dan analisis SWOT Marketing PR Humas Unisba dan Unissula. Dibuat klasifikasi persamaan dan perbedaan kemudian dikomparasikan sehingga hasil penelitian dapat menemukan model perencanaan Marketing $P R$ di perguruan tinggi islam swasta dan diagram analisis SWOT Marketing PR PTIS.

Teknik pengumpulan data pada penelitian ini dilakukan dengan
(1) Indepth-Interview (Wawancara Mendalam) dengan Kepala Bagian Humas Unisba, Kepala UPT Humas dan Marketing Unissula, Wakil Rektor I dan II Unisba, Wakil Rektor III Unissula, dan Humas SMA BPI 1 Kota Bandung; (2) Observasi, peneliti melakukan pengamatan mendalam terhadap kegiatan Marketing $P R$ Unisba dan Unissula sejak awal tahun 2015 dan ikut serta dalam beberapa kegiatan Marketing PR di Unisba dan Unissula; dan (3) Studi Pustaka, mengkaji buku, jurnal ilmiah, dan artikel yang berkaitan dengan materi Marketing PR.

\section{PEMBAHASAN}

\section{Perencanaan dan pengembangan 'marketing PR' di Unisba}

Berdasarkan hasil observasi peneliti, tahapan proses perencanaan Marketing PR Unisba adalah sebagai berikut: (1) Tahapan Pengumpulan Data dan Fakta Lapangan. Tahapan ini dimulai dari mengumpulkan data hasil evaluasi kegiatan marketing PR tahun sebelumnya, kegiatan mana yang efektif dan kegiatan mana yang kurang efektif. Riset formal dilakukan dengan melakukan penelitian terhadap calon mahasiswa. Riset informal dilakukan dengan cara melakukan wawancara kepada guru bimbingan karir, siswa, mahasiswa baru, dan wartawan. Selain itu melakukan forum group discussion (FGD) dengan tim promosi dari fakultas-fakultas; (2) Perencanaan Program Marketing $P R$. Berdasarkan hasil pengumpulan data-data dari lapangan dan melakukan evaluasi terhadap kegiatan marketing $P R$. Kepala bagian Humas bersama staf membuat perencanaan program marketing $P R$ beserta anggarannya; (3) Konsultasi dengan Wakil Rektor I dan II. Secara organisatoris Humas Unisba berada di bawah Wakil Rektor Bidang Administrasi dan Keuangan, namun untuk perencanaan marketing $P R$ dikonsultasikan juga ke 
Wakil Rektor Bidang Akademik; (4) Pengesahan Program dan Anggaran Marketing PR di Tingkat Universitas dan Yayasan. Pihak Yayasan dan pimpinan Universitas melakukan evaluasi terhadap berbagai kegiatan yang sudah dilakukan civitas akademika Unisba, termasuk terhadap kegiatan Marketing PR. Program Marketing PR disahkan bersamaan dengan anggarannya oleh yayasan dan pimpinan Universitas dalam rapat Senat Universitas; (5) Pelaksanaan Program Marketing PR. Pelaksanaan dikoordinasikan dengan situasi lapangan, misalkan untuk pelaksanaan roadshow (presentasi ke sekolah) dari bulan Septermber dan Oktober sudah berkoordinasi dengan pihak sekolah untuk menentukan waktu pelaksanaan. Untuk iklan di media cetak, elektronik, dan virtual koordinasi dengan Wakil Rektor bidang akademik sebagai penanggungjawan penerimaan mahasiswa baru (PMB); dan (6) Evaluasi Program Marketing PR. Tahapan evaluasi program marketing $P R$ dilakukan pada saat akhir tahun anggaran, evaluasi dilakukan berdasarkan pada kegiatan, hasil dan manfaatnya.

\section{Proses perencanaan 'marketing PR' di Unissula}

Berdasarkan hasil temuan lapangan maka proses perencanaan marketing PR Unissula adalah sebagai berikut: (1) Tahapan Pengumpulan Data dan Fakta di Lapangan. Penelitian ini rutin dilakukan di akhir tahun anggaran dalam upaya mendapatkan hasil temuan kegiatan marketing PR mana saja yang efektif dan berkontribusi terhadap peningkatan jumlah calon mahasiswa. Selain itu di setiap event, presentasi, openhouse, pameran selalu diminta feedback dari target audiens, melalui pengisin semacam kuesioner untuk target; (2) Rapat SP4 (Sistem Perencanaan Penyusunan Program dan Anggaran) dengan Pimpinan
Fakultas untuk Membuat Perencanaan Program Marketing PR; (3) Rapat SP4 dilakukan menjelang akhir tahun anggaran, rapat ini dilaksanakan dalam upaya membuat rencana anggaran setahun ke depan bersama pimpinan fakultas; (4) Konsultasi dengan Wakil Rektor bidang Kemahasiswaan dan Wakil Rektor Bidang Keuangan dan Administrasi. Perencanaan dikonsultasikan kepada Wakil Rektor bidang kemahasiswaan yang secara organisatoris membawahi UPT Humas dan Pemasaran. Konsultasi ini lebih fokus pada pada kegiatan dan waktu pelaksanaannya, sedangkan untuk anggaran dikonsultasikan kepada Wakil Rektor Bidang Adminstrasi dan Keuangan; (5) Konsultasi dengan Rektor. Perencanaan program marketing $P R$ yang sudah disetujui oleh Wakil Rektor Bidang Adminitrasi dan Keuangan dan kemahasiswaan, dikonsultasikan kembali dengan Rektor; dan (6) Konsultasi dengan Yayasan. Berdasarkan hasil wawancara dengan Wakil Rektor Bidang Kemahasiswaan, pihak yayasan Unissula tidak begitu susah untuk mengeluarkan dan menyetujui kegiatan universitas. Apabila sudah ada persetujuan dari pimpinan Universitas, yayasan akan menyetujui kegiatan dan anggaran yang diajukan: (a) Pelaksanaan Program Marketing PR. Program marketing PR dilaksanakan sesuai dengan jadual yang telah ditentukan. Pelaksanaan program ini dibantu oleh mahasiswa, fakultas dan alumni. Divisi marketing melakukan koordinasi dengan pihak sekolah untuk menentukan waktu pelaksanaan roadshow dan presentasi. Melakukan kerjasama dengan media untuk kegiatan publikasi, publisitas, dan juga mempersiapkan melaksanakan event safari ramadhan; dan (b) Evaluasi Program Marketing $P R$. Evaluasi program marketing $P R$ dilakukan setiap event atau kegiatan itu dilaksanakan. Selain itu untuk evaluasi di media sosial, menggunakan 
google analytic untuk mengevaluasi website Unissula, mengukur sejauh mana publikasi yang dilakukan. Berikut adalah gambar proses perencanaan dan pengembangan marketing PR Unissula:

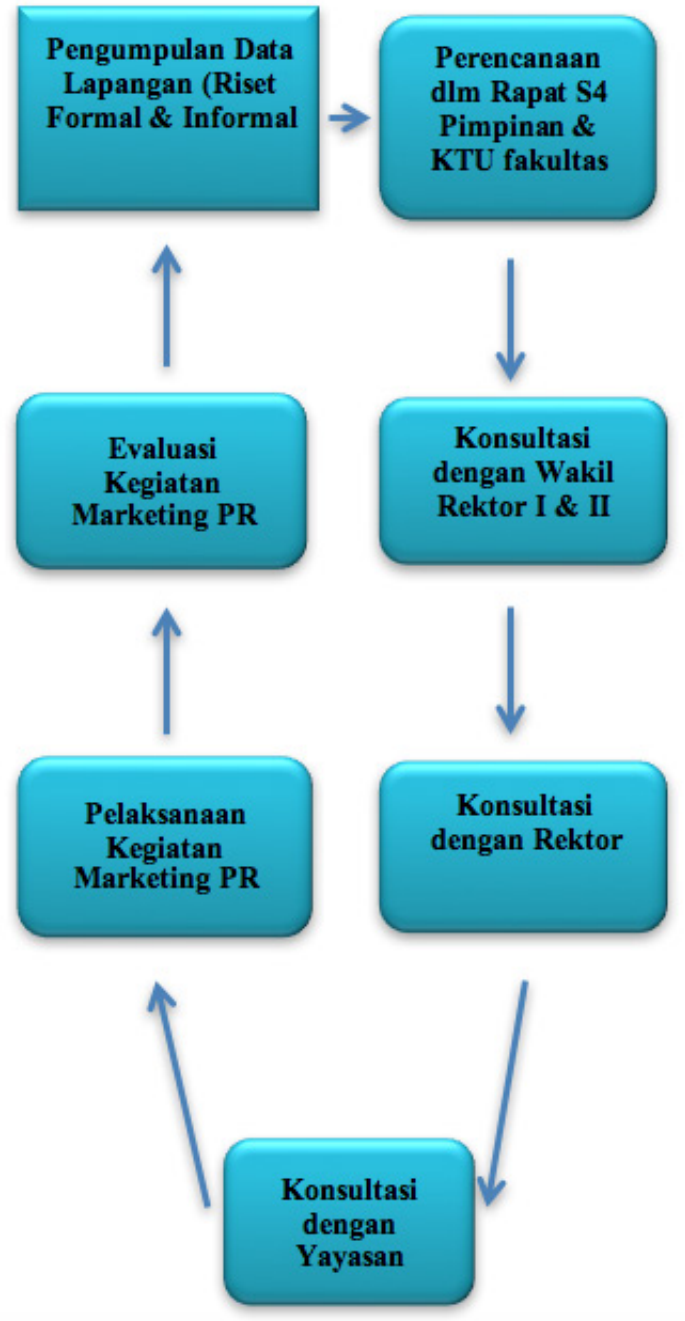

GAMBAR 1. Proses Perencanaan dan Pengembangan Marketing PR Unisba

Sumber: hasil penelitian peneliti

Model proses manajemen relasi dasarnya adalah model empat tahapan manajemen, yaitu: (1) analisis, (2) perencanaan, (3) implementasi, dan (4) evaluasi (Heath, 2005). Penelitian Lina Sinatra Wijaya dan Krismiyanti, yang berjudul Identifyng Marketing PR Strategies Implementied in Private Universities fir increasing Intake in Central Java-Indonesia dalam Journal of Art, Science \& Commerce
(2013), menjelaskan bahwa penerapan strategi Marketing PR dimulai dari; (1) perencanaan, (2) pelaksanaan, dan (3) evaluasi. Dalam konteks penelitian ini proses perencanaan program marketing PR merupakan bagian dari upaya lembaga membangun relasi dengan publiknya untuk menciptakan relasi yang positif dengan menggunakan komunikasi dua arah secara timbalbalik. Relasimerupakan fokus atau inti dari kegiatan public relations, relasi ini direpresentasikan oleh pola-pola interaksi, transaksi, pertukaran, dan keterhubungan antara organisasi dan publiknya.

Teori Manajemen Relasi (Ledingham) menjelaskan bahwa komunikasi ditempatkan sebagai alat untuk membangun relasi dan program dievaluasi berdasarkan dampaknya pada relasi antara organisasi dan publik (Kriyantono, 2014). Dalam proses perencanaan program Marketing PR, komunikasi yang dilakukan Humas Unisba dan Unissula dengan siswa, guru dan pihak sekolah merupakan dasar atau landasan untuk membuat tahapan perencanaan, tanpa ada komunikasi yang dilakukan diantara kedua belah pihak maka perencanaan dan program marketing PR tidak bisa terlaksana. Komunikasi berperan sebagai alat inisiasi, mengembangkan, dan memelihara relasi dengan publik.

Dalam proses relasi yang dilakukan Humas dengan siswa, guru dan pihak sekolah terjadi pertukaran persepsi, atribut, dan identitas yang berbeda, dan diantara keduanya dimungkinkan saling mempengaruhi. Adanya kegiatan komunikasi yang intens antara Humas dan pihak sekolah dapat menciptakan relasi jangka panjang dan loyalitas terhadap lembaga. Hal ini dapat dilihat dengan adanya beberapa sekolah yang memang loyal terhadap Unisba dan Unissula. Manajemen relasi seperti inilah yang harus dipertahankan oleh Unisba dan Unissula, 
dimana ada kedekatan emosional antara pihak sekolah dengan perguruan tinggi. Aspek kedekatan emosional sebaiknya dibangun dalam menjalin relasi dengan pihak sekolah, dimana relasi dibangun oleh kebutuhan dan keinginan dari kedua belah pihak. Model perencanaan dan pengembangan Marketing PR menciptakan atmosfir 'take and give' dimana lembaga dan publik berupaya mencapai konsensus dan kolaborasi. Humas harus bisa berperan sebagai co-creator dalam proses perencanaan program PR dan juga dalam membangun relasi dengan publiknya. Humas Unisba dan Unissula berperan sebagai co-creator dari proses pemaknaan, interpretasi dan perumusan perencanaan yang berlandaskan pada misi dan visi lembaga. Analisis SWOT dalam konteks penelitian ini merupakan singkatan dari lingkungan Internal Strengths dan Weaknesses serta lingkungan eksternal Oppurtunities dan Threats yang dihadapi dalam Marketing $P R$ di PTIS. Analisis ini membandingkan antara faktor eksternal peluang dan ancaman dengan faktor internal kekuatan dan kelemahan. Berdasarkan faktorfaktor tersebut dapat diambil oleh Humas dan Pimpinan PTIS dalam menghadapi

TABEL 1. Matriks Analisis SWOT Marketing PR Unisba.

(sumber: hasil wawancara dan analisis peneliti)

Eksternal Internal

Peluang (O)

(a) Memiliki 11 fakultas dan 36 studi yang terdiri dari beberapa kluster, (b) sebagai universitas Islam memungkinkan untuk bekerjasama dengan pesantren di dalam dan luar negeri, (c) menerapkan BUDAI sebagai basis pendidikan karakter di berbagai disiplin ilmu, (d) Memiliki jumlah alumni yang potensial menjadi mitra dalam memasarkan Unissula.

\section{Ancaman (T)}

(a) Strategi diskon yang dilakukan PT lain, (b) sponsorship yang diberikan perguruan tinggi lain, dan (c) strategi branding dari PT lain yang tematik dan terukur.

Kekuatan (S)
SDM yang unggul dalam pemasaran
dan kehumasan, media relations
yang baik, kualitas publisitas yang
memadai, tampilan website sebagai
brand image sudah atraktif, Brand
positioning sebagai Universitas
Islam yang mempunyai budaya
akademik Islam, kerja sama dengan
sekolah terjalin dengan baik, tingkat
kepercayaan orangtua tinggi,
Penggunaan semua saluran sosial
media sebagai marketing tools, dan
Word of Mouth yang cukup tinggi

Strategi SO

(a) Perencanaan Marketing PR yang (a) Ada target untuk terintegrasi dengan fakultas dan menyampaikan berita di program studi, (b) Meningkatkan media massa dan virtual, (b) kerjasama dengan pondok Mengedukasi calon mahasiswa pesantren, sekolah, perguruan berkaitan dengan informasi tinggi dalam dan luar negeri, (c) Peneriamaan Mahasiswa Baru, Memperkuat budaya akademik dan (3) Mengedukasi civitas Islam untuk civitas akademika, akademi mengenai konsep PR dan (d) Melibatkan alumni dalam dan branding Islam Marketing PR

\begin{tabular}{|c|c|}
\hline Strategi ST & Strategi WT \\
\hline $\begin{array}{l}\text { (a) Membuat program Marketing } \\
\text { PR bernilai keislaman yang } \\
\text { menarik, efektif, dan efesien dan (b) } \\
\text { Memperkuat sosial media sebagai } \\
\text { marketing tools }\end{array}$ & $\begin{array}{l}\text { (a) Memperbanyak beasiswa } \\
\text { untuk mahasiswa berprestasi } \\
\text { dan kurang mampu, (b) } \\
\text { Memperkuat sinergi program } \\
\text { kerja Humas dengan fakultas, } \\
\text { dan (c) Meningkatkan kualitas } \\
\text { akademik dan mutu pelayanan. }\end{array}$ \\
\hline
\end{tabular}


persaingan yang semakin kompetitif di era MEA.

\section{Strategi 'strengths-oppurtunities'}

(a) Perencanaan Marketing $P R$ yang terintegrasi dengan fakultas dan program studi. Dalam konteks ini Humas harus menjadi koordinator kegiatan Marketing $P R$ di universitas dan berkoordinasi dengan tim promosi dari fakultas ataupun program studi. (b) Meningkatkan kerjasama dengan pondok pesantren, sekolah, perguruan tinggi, dan stakeholders di dalam negeri dan luar negeri. Di era MEA ini terbuka kesempatan untuk membangun kerjasama dengan luar negeri, selama ini Unissula membangun kerjasama dengan pondok pesantren di sekitar Jawa Tengan. (c) Memperkuat budaya akademik Islam (BUDAI) untuk civitas akademika. Berdasarkan hasil observasi peneliti, Unissula sudah menjalankan syariat Islam melalui BUDAI. Aturan ditegakkan dan ada sangsi bagi dosen, karyawan, dan mahasiswa apabila melakukan pelanggaran. Inilah bagian dari identitas korporat Unissula yang harus diperkuat dan dipromosikan kepada publik. (d) Melibatkan alumni dalam Marketing $P R$. Di era MEA ini bukan hanya Humas dan civitas akademika yang harus terlibat dalam kegiatan Marketing PR tetapi juga alumni. Alumni dilibatkan dalam kegiatan Marketing $P R$ di daerah, karena biasanya ada kedekatan emosional apabila berasal dari satu daerah.

\section{Strategi 'weaknesses - oppurtunities'}

(a) Ada target untuk menyampaikan berita di media massa dan virtual. Humas mempunyai target agar berita tentang perguruan tinggi dapat muncul di media massa dua sampai tiga kali dalam seminggu. Ini dilakukan agar publik mengingat terus tentang eksistensi perguruan tinggi. Begitu juga dengan di media virtual, postingan berita di media virtual dapat diakses oleh publik internal dan eksternal. (b) Mengedukasi calon mahasiswa dengan informasi mengenai penerimaan mahasiswa baru (PMB). Semua informasi yang berkaitan dengan PMB harus disampaikan secara detail kepada siswa, guru, dan orangtua sehingga tidak ada prasangka bahwa biaya kuliah di Unissula mahal. (c) Mengedukasi civitas akademika mengenai konsep public relations dan branding Islam. Humas harus menjelaskan kepada publik internal tentang peran dan tugas Humas di lembaga sehingga tidak ada prasangka negatif mengenai UPT Pemasaran dan Humas. Dan juga memberikan penjelasan tentang branding Islam yang harus dijaga oleh civitas akademika melalui aspek sikap, perilaku, dan opini.

\section{Strategi 'strengths - threats'}

(a) Membuat program Marketing $P R$ bernilai keislaman yang menarik, efektif, dan efesien. Strategi perencanaan program Marketing $P R$ diawali dengan riset formal dan informal, dan hasil evaluasi kegiatan Marketing $P R$ tahun sebelumnya dijadikan sebagai bahan evaluasi. Program dan pemilihan media harus disesuaikan dengan target sasaran yang dituju, buatlah program Marketing $P R$ yang disesuaikan dengan kebutuhan sasaran. (b) Memperkuat penggunaan sosial media sebagai marketing tools. Secara organisatoris UPT Humas dan Pemasaran Unissula mempunyai divisi website dan social media maintenance, artinya secara teori sudah ideal tinggal memaksimalkan penggunaan sosial media yang banyak digunakan siswa sebagai marketing tools.

\section{Strategi 'weaknesses - threats'}

(a) Memperbanyak beasiswa untuk mahasiswa berprestasi dan kurang mampu. Strategi ini digunakan dalam upaya menarik siswa berprestasi dan kurang mampu untuk kuliah di Unissula. 
Beasiswa juga sudah diberikan kepada siswa yang hafidz Al-Qur'an 30 juz. (b) Memperkuat sinergi program kerja Humas dengan fakultas. Dalam proses perencanaan Marketing $P R$ di Unissula ada tahapan rapat SP4 (Rencana Anggaran Tahunan) pimpinan dan kepala tata usaha (KTU) fakultas. Rapat ini dilakukan dalam upaya menyinergikan program kerja Humas dan fakultas sehingga lebih efektif dan efesien. (c) Meningkatkan kualitas akademik dosen dan mahasiswa serta mutu pelayanan untuk publik internal dan eksternal sebagai bagian dari promosi untuk masyarakat. Berdasarkan hasil penelitian peneliti terhadap analisis SWOT Marketing $P R$ di Unisba dan Unissula, maka peluang dan tantangan kegiatan Marketing PR PTIS di era MEA dapat dilihat dari kombinasi faktor internal dan eksternal. Perguruan Tinggi Islam Swasta dapat memanfaatkan peluang yang ada dalam upaya menghadapi tantangan di era MEA.

Hasil penelitian ini dapat dijadikan sebagai input Humas PTIS dalam menyusun strategi perencanaan Marketing $P R$ dalam upaya meningkatkan jumlah mahasiswa baru dan dalam upaya

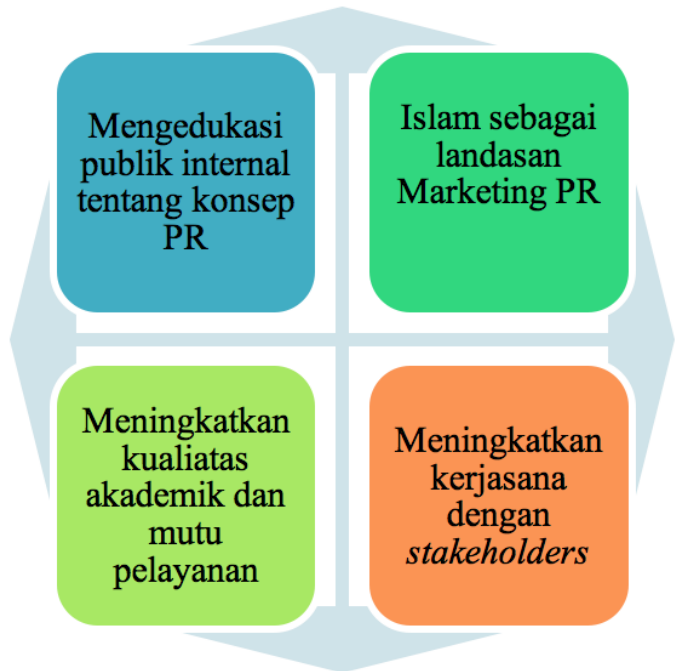

GAMBAR 2. Diagram Analisis SWOT PTIS (sumber: hasil penelitian peneliti) memperkuat citra sebagai perguruan tinggi Islam swasta. Zuhrotun Nisak (2014) dalam penelitian yang berjudul Analisis SWOT untuk Menentukan Strategi Kompetitif, menjelaskan bahwa,

"Dengan meningkatnya persaingan global, perusahaan dituntut untuk selalu memperhatikan keadaan pasar dan bersaing lebih kompetitif dalam menentukan strategi. Strategi kompetitif merupakan salah satu cara untuk mengetahui daya saingnya di setiap kekuatan. Penggunaan analisis SWOT yang efektif dapat memegang peranan penting dalam menentukan strategi kompetitif, agar dapat mengetahui kekuatan, kelemahan, peluang, dan ancaman yang dihadapi perusahaan".

\section{SIMPULAN}

Perencanaan Marketing $P R$ tidak terlepas dari proses operasional PR Cutlip, Center, dan Broom, dimulai dari tahapan defining PR problems, planning and programming, taking action and communicating, dan evaluating the programm. Hal yang mendasar dari perencanaan Marketing $P R$ di PTIS adalah membangun manajemen relasi dengan siswa, guru, sekolah dan stakeholders melalui kegiatan komunikasi yang berkesinambungan.

Peluang dan tantangan startegi Marketing PR dalam analisis SWOT dapat dilihat dari aspek: (a) Strategi StrengthsOppurtunities, yaitu mempertahankan dan memperkuat nilai Islam dalam kegiatan Marketing PR; (b) Strategi WeaknessesOppurtunities, yaitu mengedukasi publik internal tentang konsep Public Relations dan Marketing $P R$ agar tidak terjadi kesalahan persepsi dan prasangka; (c) Strategi Strengths-Treats, artinya di era MEA ini PTIS harus meningkatkan kerjasama dengan stakeholders di dalam maupun luar negeri; (d) Strategi Weaknesses-Treats adalah meningkatkan 
kualitas akademik dosen dan mahasiswa, serta mutu pelayanan prima bagi publik internal dan eksternal.

\section{DAFTAR PUSTAKA}

Gregory, Anne. (2001). Perencanaan dan Manajemen Kampanye Public Relations. Jakarta. Penerbit Erlangga.

Harris, Thomas L. (1991). The Marketer's Guide to Public Relations. New York. John Wilwy and Son Inc.

Heat, Robert L. (2005). Encyclopedia of Public Relations, volume $1 \& 2$. London:Sage Publicatios Inc.
Kriyantono, Rachmat. (2014). Teori Public Relations Perspektif Barat \& Lokal; Aplikasi Penelitian dan Praktik. Jakarta. Kencana Prenamedia Group.

Nisak, Zuhrotun. (2014). Analisis SWOT untuk Menentukan Strategi Kompetitif. http://journal.unisla. ac.id/pdf/12922013/4.pdf

Pikiran Rakyat. (2016, 27 Juni).

Soemanagara. (2012). Strategic Marketing Communication, Konsep Strategis dan Terapan. Bandung. Penerbit Alfabeta.

Yin, R. K. (2011). Studi Kasus: Desain dan Metode. Jakarta: Rajawali Press. 